Bond University

Research Repository

\title{
Authors' response to Atee et al
}

Pu, Lihui; Moyle, Wendy; Jones, Cindy; Todorovic, Michael

Published in:

Maturitas

DOI:

10.1016/j.maturitas.2020.12.007

Licence:

CC BY-NC-ND

Link to output in Bond University research repository.

Recommended citation (APA):

Pu, L., Moyle, W., Jones, C., \& Todorovic, M. (2021). Authors' response to Atee et al. Maturitas, 145, 87-88. https://doi.org/10.1016/j.maturitas.2020.12.007

\section{General rights}

Copyright and moral rights for the publications made accessible in the public portal are retained by the authors and/or other copyright owners and it is a condition of accessing publications that users recognise and abide by the legal requirements associated with these rights.

For more information, or if you believe that this document breaches copyright, please contact the Bond University research repository coordinator. 


\section{Letter to the Editor}

\section{Authors' response to Atee et al.}

Lihui $\mathrm{Pu}, \mathrm{PhD}^{1,2 *}$, Wendy Moyle, $\mathrm{PhD}^{1,2}$, Cindy Jones, $\mathrm{PhD}^{2,3}$, Michael Todorovic, $\operatorname{PhD}^{1,2}$

${ }^{1}$ School of Nursing and Midwifery, Griffith University, Australia

${ }^{2}$ Menzies Health Institute Queensland, Griffith University, Australia

${ }^{3}$ Faculty of Health Sciences \& Medicine, Bond University, Australia

Corresponding author:

*Lihui $\mathrm{Pu}, \mathrm{PhD}$

Menzies Health Institute Queensland, Griffith University, 2.18 Health Sciences (N48),

170 Kessel Rd, Nathan, Brisbane, Queensland, 4111, Australia.

E-mail address: lihui.pu@griffithuni.edu.au 
We thank you for the opportunity to respond to the comments raised in Atee et al.'s letter to the editor [1] and thank Mr Atee and his colleagues for their interest in our paper [2].

1) $\mathrm{Mr}$ Atee et al. are concerned about the confounding effect of prescribed psychotropic medications on sleep outcomes. In our paper, we had shown that participants' medication usage, as measured by the Medication Quantification Scale-III (MQS-III), at baseline was similar in both the intervention and control groups (Table 1). While we acknowledge that medication can have an impact on both groups, in this instance, we believe that medication use had minimal impacts on the study outcomes. However, future larger-scale studies should be mindful of this potential issue and, if necessary, appropriately adjust for its effect during data analysis.

2) Mr Atee et al. raise concerns about the use of proxy pain assessments for the total sample, including those who might have had the ability to verbalize their pain experience, and about not using a validated pain assessment tool in the study. In this study, proxy assessments of pain (e.g., pain frequency, onset, intensity, locations, and nonpharmacological therapies) were collected through structured interviews with the nursing staff who had regular contact with the resident. This approach is considered to be an appropriate method to collect pain-related information for people with dementia [2]. We do agree that self-reports should where possible be obtained from all participants, especially those with mild cognitive impairment [3]. However, most participants in this study had severe cognitive impairment, with an average MMSE score of $9.93( \pm 8.05)$, and data collection/analysis of the self-reported pain before and after each intervention session was not achievable. Moreover, there were also fluctuations in individuals' ability to describe their pain level, even for those with mild cognitive impairment, and this resulted in a large amount of missing data in self-reported

pain. Therefore, a decision was made to use the observational pain measurement - Pain Assessment in Advanced Dementia Scale (PAINAD), a valid observational pain assessment 
tool for people with advanced dementia [4] - as the primary measurement of pain for all participants, and this allowed the total sample data to be included in the data analysis, which was reported as the primary outcome in our previously published paper [5].

3) $\mathrm{Mr}$ Atee et al. question the definition of chronic pain used. We agree that the decision concerning whether or not someone with advanced dementia was in chronic pain could be contested. However, this is because the self-reporting of pain, which is the gold standard for pain assessment, is compromised in this group. In this study, residents with chronic pain were identified if they were prescribed regular pain medications or if there was an indication of pain from the staff, as surrogate measures of pain. We believe that these methods are reasonable in people with dementia who are considered to be experiencing chronic pain.

Furthermore, all participants in this study had experienced chronic pain ( $>3$ months) and had at least one pain-related condition (osteoarthritis, fracture/fall, low back pain and stroke, etc.). As the objective of this study was focused on the secondary outcomes of sleep and motor activity, pain-related information was reported in the previously published paper [5].

In summary, our results provide preliminary support for the hypothesis that the PARO intervention could potentially improve sleep for long-term care residents with dementia and chronic pain. We acknowledge that the assessment of pain is challenging in people with dementia, and we are undertaking further work to understand the effect of social robot interventions and using technologies to help pain assessment in this group.

\section{Conflict of interest}

The authors declare that they have no conflict of interest in relation to this letter.

\section{Funding}

No funding was received in relation to this letter. 


\section{References}

[1] M. Atee, T. Morris, S. Macfarlane, C. Cunningham, Letter to the editor regarding Pu L. et al. (2020), "The effect of a social robot intervention on sleep and motor activity of people living with dementia and chronic pain: A pilot randomized controlled trial”, Maturitas (2020).

[2] A. Corbett, K.-M. Nunez, E. Smeaton, I. Testad, A.J. Thomas, S.J. Closs, M. Briggs, L. Clifton, M.T. Gjestsen, V. Lawrence, The landscape of pain management in people with dementia living in care homes: a mixed methods study, Int J Geriatr Psychiatry 31(12) (2016) 1354-1370.

[3] K. Herr, P.J. Coyne, M. McCaffery, R. Manworren, S. Merkel, Pain assessment in the patient unable to self-report: Position statement with clinical practice recommendations, Pain Manag Nurs 12(4) (2011) 230-250.

[4] V. Warden, A.C. Hurley, L. Volicer, Development and psychometric evaluation of the Pain Assessment in Advanced Dementia (PAINAD) Scale, J Am Med Dir Assoc 4(1) (2003) 9-15.

[5] L. Pu, W. Moyle, C. Jones, M. Todorovic, The effect of using PARO for people living with dementia and chronic pain: A pilot randomized controlled trial, J. Am. Med. Dir. Assoc. 21(8) (2020) 1079-1085. 
Table 1

Demographics and medical conditions of participants with SenseWear data

\begin{tabular}{lccc} 
Variables & $\begin{array}{c}\text { Control group } \\
(\mathrm{n}=20)\end{array}$ & $\begin{array}{c}\text { Intervention group } \\
(\mathrm{n}=21)\end{array}$ & $p$ value \\
\hline Age $^{*}$ & $85.50 \pm 6.02$ & $86.48 \pm 8.81$ & $0.234^{\dagger}$ \\
& $86.5(72,93)$ & $90(65,97)$ &
\end{tabular}

Gender

Female

$\begin{array}{lcc}11(55.0 \%) & 18(85.7 \%) & 0.033 \\ 9(45.0 \%) & 3(14.3 \%) & \end{array}$

Male

Dementia subtypes

Alzheimer's disease

$7(35.0 \%)$

$3(15.0 \%)$

$1(5.0 \%)$

Frontal-temporal dementia

$9(45.0 \%)$

$0.766^{\S}$

Dementia unspecified

Living unit

Secure dementia unit

$9(45.0 \%)$

0.354

Facility unit

$11(55.0 \%)$

$13(61.9 \%)$

$8(38.1 \%)$

Facility room-type

Single room

$18(90.0 \%)$

$9(42.9 \%)$

$2(9.5 \%)$

$0(0.0 \%)$

$10(47.6 \%)$

Shared room

$2(10.0 \%)$

$18(85.7 \%)$

$1.000^{\S}$

Activity level

Ambulatory

$1(5.0 \%)$

$11(55.0 \%)$

$3(15.0 \%)$

$5(25.0 \%)$

$3(14.3 \%)$

Assistive devices

Wheelchair

Bedridden

$10(50.0 \%)$

$4(19.0 \%)$

$0.280^{\S}$

Walking exercise, yes

Admission month*

$33.2 \pm 29.32$

$25(3,100)$

$6(28.6 \%)$

$3(14.3 \%)$

$8(38.1 \%)$

$15(71.4 \%)$

$0.160^{+}$

$\mathrm{MMSE}^{*}$

$11.55 \pm 8.06$

$(0,23)$

$24.8 \pm 23.68$

$0.449^{\dagger}$

$16(3,99)$

MMSE $<11$

$9(45.0 \%)$

$7.71 \pm 7.84$

$0.114^{\dagger}$

BMI $^{*}$

$25.10 \pm 7.04$

$(0,24)$

$(16.4,49.6)$

$15(71.4 \%) \quad 0.086^{\dagger}$

$22.12 \pm 4.93$

$0.134^{\dagger}$

The intensity of pain

$(11.83,35.8)$

No pain

Mild

$1(5.0 \%)$

$7(33.3 \%)$

$8(40.0 \%)$

$6(28.6 \%)$

Moderate

$11(55.0 \%)$

$7(33.3 \%)$

Severe

$0(0.0 \%)$

$1(4.8 \%)$

$0.486^{\S}$ 


\begin{tabular}{lccc}
\hline Variables & $\begin{array}{c}\text { Control group } \\
(\mathrm{n}=20)\end{array}$ & $\begin{array}{c}\text { Intervention group } \\
(\mathrm{n}=21)\end{array}$ & $p$ value \\
\hline Nurse-estimated pain score $^{*}$ & $3.05 \pm 2.09$ & $3.24 \pm 2.49$ & $0.915^{\dagger}$ \\
& $3(0,8)$ & $3(0,9)$ & \\
MQS score for medication $^{*}$ & $14.54 \pm 8.59$ & $14.56 \pm 7.86$ & $0.896^{\dagger}$ \\
& $13.5(2.2,36.9)$ & $12.4(3.8,33.7)$ & \\
\hline
\end{tabular}

Note. ${ }^{*}$ values presented as Mean $\pm S D$ median (range), Bold values are statistically significant $(p<.05)$. Abbreviations: SD, Standard Deviation; MMSE, Mini-Mental State Examination; BMI, Body Mass Index; MQS, Medication quantification scale-III.

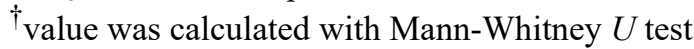

*alue was calculated by Chi-square test

$\S_{\text {value was calculated by Fisher's exact test }}$

$\|_{\text {value was calculated with independent } t \text {-test }}$ 